\title{
Haemophilia nursing practice: A global survey of roles and responsibilities
}

Kate Khair, Mahmoud Abu-Riash, Ana Claudia Acerbi, Marlene Beijlevelt, Georgina Floros, Kuixing Li, Ljiljana Rakić, Bongi Mbele, Robyn Shoemark, Jim Munn

Haemophilia nursing roles continue to develop alongside nursing as a profession. There are now nurses who practice autonomously, much like a medical practitioner, and many who have extended their roles to deliver direct patient care, education and research. There has been little, if any, comparison with haemophilia nurse roles internationally, nor of the impact of these roles on patient reported outcomes. This paper reports the results of an international survey, of 297 haemophilia nurses from 22 countries, describing current day practice and care. Many nurses work above and beyond their funded hours to improve care through research and evidence-based practice. While some are able to attend international meetings to report and discover this evidence, many due to financial constraints, are not. Others reported difficulty with communicating in English, which limited congress attendance. With on-line learning capability, sharing of best practice is now possible, and this approach should be a platform developed in coming years to further enhance haemophilia nursing practice and ultimately patient care.

Keywords: haemophilia nurses, clinical experience, evidence-based care, patient outcomes

Research is required to further the development of care for patients and their families, according to the authors of the European Principles of Haemophilia Care, published in 2008 [1]. They wrote that this research should include examination of different service delivery models, outcomes and quality of life measures; nurses were recognized as being key

Kate Khair, Haemophilia Centre, Great Ormond Street Hospital for Children NHS Foundation Trust, London WC1N 3JH UK. Email: Kate.Khair@gosh.nhs. uk

Mahmoud Abu-Riash, Oncology Center, King Faisal Specialist Hospital and Research Center, P.O. Box 3354, Riyadh 11211, Saudi Arabia.

Ana Claudia Acerbi, Federal University of São Paulo, São Paulo, Brazil Marlene Beijlevelt, Haemophilia Treatment Centre, Academic Medical Centre, Meibergdreef 9, 1105 Amsterdam, The Netherlands.

Georgina Floros, Hemophilia Centre, St Michael's Hospital, Toronto, Ontario M5B 1W8, Canada

Kuixing Li, Department of Hematology, Peking Union Medical College Hospital, Peking, China.

Ljiljana Rakić, Haemophilia Centre and Blood Transfusion Institute of Serbia. 11000 Belgrade, Serbia.

Bongi Mbele, Haemophilia Comprenhensive Clinic, Charlotte Maxeke Academic Hospital, Parktown, Johannesburg 2001, South Africa.

Robyn Shoemark, The Children's Hospital at Westmead, Sydney, New South Wales, Australia.

Jim Munn, University of Michigan - Hemophilia and coagulation disorders Program, 1500 E. Med Cr. Dr. Ann Arbour, Michigan, USA.

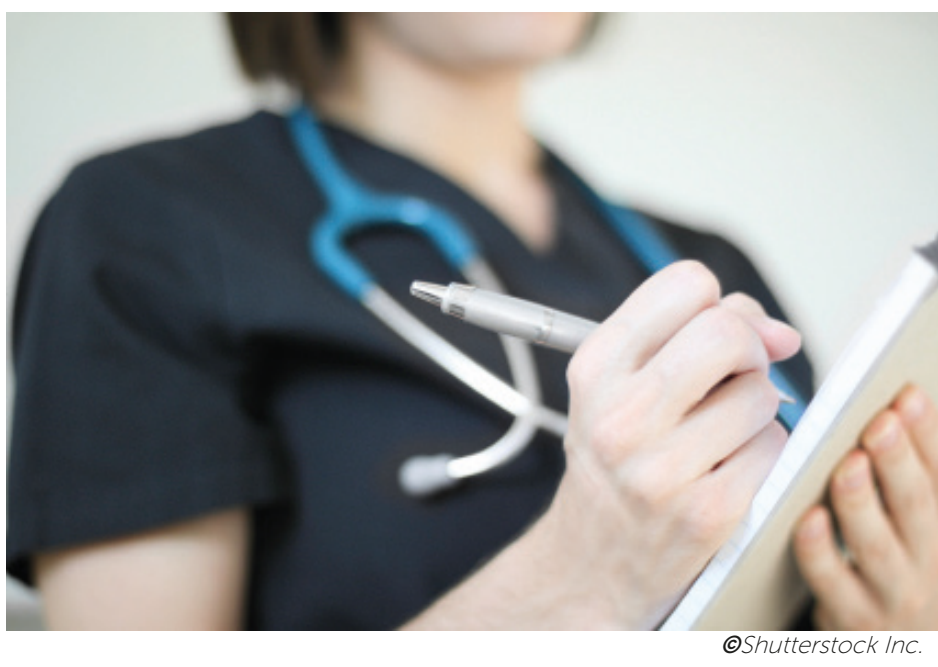

players in promoting this evidence. A survey published in 2012 found that UK haemophilia nurses demonstrated "an acceptance that care can be improved for patients and their families through implementing research into clinical care" [2]. Nevertheless, the survey found that few haemophilia nurses actually engaged in nurse-led research. Since then haemophilia nursing research has gained a greater profile within the published literature. Mostly research is qualitative in nature and focuses on patient outcomes and care; the published research is skewed towards the developed world, where affected individuals have relatively ready access to specialist care.

The World Federation of Haemophilia (WFH) nurses committee (WFHNC) is a subcommittee of the WFH that focuses on nurse education and training to enhance patient care and outcomes. This paper describes a project established by the WFHNC to understand how haemophilia nurses practice globally, their needs and requirements to augment their skills, and to investigate areas where nurses can enhance nursing and patient care through improved clinical practice using evidence-based care, particularly in those countries where there is limited access to diagnosis, factor concentrates and home therapy.

\section{Methods}

The WFHNC devised a questionnaire designed to explore the existing clinical experience, attitudes and barriers towards developing evidence-based care for haemophilia nursing globally. Invitations to a customisable web-based survey programme (SurveyMonkey) were sent by email to all haemophilia nurses known to the WFHNC. Instructions 
for completing the study were translated into numerous languages to facilitate wider uptake of the study. The questionnaire was translated into Portuguese and Chinese for nurses in Brazil and China who completed the study using a paper and pencil questionnaire. Responses to free text questions were then back translated into English and entered onto the SurveyMonkey database to ensure full data capture.

As well as answering multiple choice response questions on the SurveyMonkey, two distinct free-text questions were asked:

- 'list up to 5 key areas in which you would like to see more haemophilia nursing education/support/research' (clinical practice) and

- 'please suggest up to 5 topics you would like to see covered in future WFH nurses meetings' (evidence base/ research practice).

Each comment was coded into a topic; the topics were then coded as recurring themes. For example 'heavy menstrual bleeding' and 'managing haemophilia carriers' were coded as a topic under the umbrella theme of 'women with bleeding disorders'. The results of these two freetext questions overlapped, particularly where evidencebased care is limited, or where there are few publications to support clinical practice. This reflects a need to develop nurse-led strategies which answer these questions (see Table 1).

\section{Results}

In all, 297 nurses from 22 counties (Figure 1) participated in the survey. These were established experienced haemophilia nurses, reporting a range from $\leq 5$ years $(n=113)$ to $\geq 20$ years $(n=51)$ as a practicing haemophilia nurse. Some 253 respondents reported having degree level education, with most reporting a BSC $(n=152), M S c(n=56)$ or $\operatorname{PhD}(n=1)$ in nursing. A further 44 nurses reported having undergraduate to Doctoral degrees in other health-related fields. $36.6 \%$ of respondents reported that their institution required them to be registered nurses, a further $31.2 \%$ requiring a diploma, $33.5 \%$ a first degree, and $3.1 \%$ masters level education to practice in their role.

Nurses mainly worked in large haemophilia centres with $42.6 \%$ of respondents reporting treating more than 100 patients with haemophilia; only $5.2 \%$ treated $\leq 5$ patients per year. Day-to-day activities were similar for nurses regardless of geographical location; these are listed in Table 2. Some nurses reported extended roles within both clinical care (e.g. nurse-led clinics and care delivery) and nurse-led research. While two-thirds (66.6\%) administered clotting factor to patients, nearly one-third $(29.0 \%)$ also prescribed it.

The majority of nurses (57\%) worked full time in haemophilia care (31-40 hours/week) with 19.5\% being funded to provide 1-10 hours haemophilia care per week. $20 \%$ of nurses reported having dedicated/funded nonclinical time for nurse-led research/enquiry. For some nurses' this 'academic time' was rostered to facilitate nurseled research; whilst others performed research in their clinical time. $83 \%$ of haemophilia nurses reported working an average of $1-\geq 10$ additional hours per week for both clinical and academic reasons, and $50 \%$ of these nurses reported this time was not funded nor recouped.

Respondents identified 381 areas in need of improved evidence base and a total of 487 research questions. These were collated into 25 clinical and 29 research themes (Table 1). The top three themes in the clinical domains were:

- Supporting nurses and nurse development $(n=80)$

- Pharmacokinetics and new extended half-life (EHL)

\section{Figure 1: The survey was completed by 297 haemophilia nurses from 22 countries}

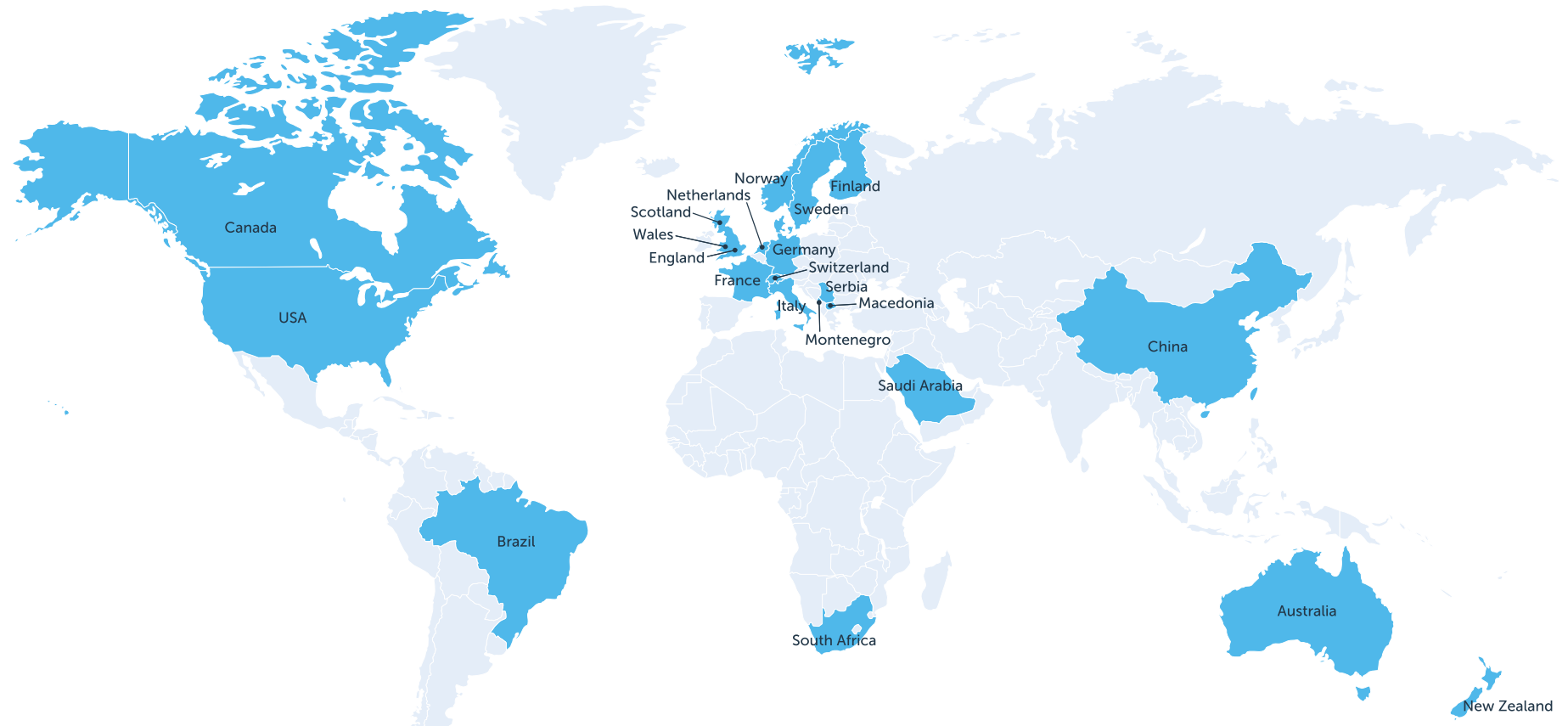


Table 1: Topics identified for improved clinical evidence and nurse-led research

\begin{tabular}{|c|c|c|c|}
\hline Areas for improved clinical evidence $(n=25)$ & $\begin{array}{l}\text { Response } \\
\text { count }\end{array}$ & Areas for nurse-led research $(n=29)$ & $\begin{array}{l}\text { Response } \\
\text { count }\end{array}$ \\
\hline Supporting nurses and nurse development & $80 *$ & Supporting nurses and nurse development in research role & 60 \\
\hline Pharmacokinetics and new extended half-life products & 37 & Managing and using new therapeutic products & 57 \\
\hline Inhibitors & 35 & Child and adolescent care & 38 \\
\hline Joint health and physiotherapy & 30 & Inhibitors & 37 \\
\hline Psychosocial support & 29 & Rare bleeding disorders including & 34 \\
\hline Rare bleeding disorders & 29 & Psychological support & 32 \\
\hline Venous access & 21 & Care delivery & 28 \\
\hline Genetics and gene therapy & 17 & Patient reported outcomes and quality of life & 26 \\
\hline Women with bleeding disorders & 14 & Physiotherapy/joint health/rehabilitation & 25 \\
\hline Caring for newly diagnosed families & 13 & Adherence & 21 \\
\hline Adolescence & 13 & Venous access & 21 \\
\hline Patient reported outcomes & 11 & Telehealth & 17 \\
\hline Care delivery & 11 & Ageing & 16 \\
\hline Telehealth & 10 & Genetics and gene therapy & 15 \\
\hline Ageing & 9 & Pain & 13 \\
\hline Blood-borne viruses & 5 & Surgery & 9 \\
\hline Mild/moderate haemophilia & 4 & Women with bleeding disorders & 8 \\
\hline Care of children & 3 & Understanding laboratory assays & 7 \\
\hline DDAVP use & 3 & Databases and data management including epidemiology & 5 \\
\hline Sexuality & 2 & Blood-borne viruses & 5 \\
\hline Tranexamic acid use & 1 & Dental care & 4 \\
\hline Supporting travelling patients & 1 & Transition & 4 \\
\hline Protocols for treatment & 1 & DDAVP use & 3 \\
\hline Surgery & 1 & Emergency Room care & 3 \\
\hline \multirow[t]{5}{*}{ Cancer } & 1 & Tranexamic acid use & 2 \\
\hline & & Insurance/funding & 2 \\
\hline & & Obesity & 1 \\
\hline & & Supporting travelling patients & 1 \\
\hline & & Thrombosis risk in haemophilia & 1 \\
\hline
\end{tabular}

products $(n=37)$

- Inhibitors $(n=35)$.

The top three research questions identified were:

- Supporting nurses and nurse development in research role $(n=60)$

- Managing and using new therapeutic products $(n=57)$

- Child and adolescentcare (self-management, adherence, transition $(n=38))$.

Communicating in English was identified as an issue that precluded nurses from participating in promotion of clinical and research care: $29.2 \%$ of respondents stated that writing was problematic; $28.6 \%$ cited difficulties in speaking in English, 24.3\% cited difficulties reading English and 23.8\% cited poor verbal understanding. This meant that many nurses never attended international meetings such as the WFH Congresses where they could present or hear about care given by nurses. Only $45 \%$ of respondents had ever attended the WFH congress and only $54 \%$ knew who was their regional WFH nursing committee member. While $45 \%$ of respondents stated they had attended WFH, $84 \%$ of these stated they had received study leave to attend international meetings. For $85 \%$ of respondents, funding was the main issue for not attending international meetings.

\section{Discussion}

This survey has highlighted many areas in the world where haemophilia nurses have an impact on direct face-to-face patient care, and are engaged in promoting nurse-led care to improve patient outcomes. That $46 \%$ of nurses do not know the identity of their regional WFH nursing committee member shows that the WFHNC has an opportunity to improve care even more by engaging with nurses within our regions. This may be particularly relevant in developing regions of the world, where support for nurses may be lacking.

It is accepted that research is required to further the development of care for patients and their families, and that this should include examination of different service delivery models, outcomes and quality of life measures. 
Table 2: Day-to-day responsibilities of haemophilia nurses

\begin{tabular}{|c|c|c|}
\hline Responses & $\begin{array}{l}\text { Response } \\
\text { count }\end{array}$ & $\begin{array}{l}\text { Per cent } \\
\text { reported }\end{array}$ \\
\hline Patient/family infusion teaching/training & 257 & $87.7 \%$ \\
\hline Education & 231 & $78.8 \%$ \\
\hline Assessment of bleeds & 229 & $78.2 \%$ \\
\hline History taking & 219 & $74.7 \%$ \\
\hline $\begin{array}{l}\text { Attending meetings in your hospital/de- } \\
\text { partment }\end{array}$ & 218 & $74.4 \%$ \\
\hline Telephone triage & 208 & $71.0 \%$ \\
\hline Taking blood samples & 203 & $69.3 \%$ \\
\hline Reviewing infusion records & 199 & $67.9 \%$ \\
\hline Patient communication with email & 196 & $66.9 \%$ \\
\hline $\begin{array}{l}\text { Administration of clotting factor concen- } \\
\text { trate (CFC) }\end{array}$ & 195 & $66.6 \%$ \\
\hline Ordering/requesting laboratory test & 188 & $64.2 \%$ \\
\hline Maintaining protocols/policies/procedures & 184 & $62.8 \%$ \\
\hline Data collection & 183 & $62.5 \%$ \\
\hline Data management/entry & 173 & $59.0 \%$ \\
\hline Liaison & 163 & $55.6 \%$ \\
\hline Creating patient treatment plans & 163 & $55.6 \%$ \\
\hline Triaging consults & 160 & $54.6 \%$ \\
\hline Other administrative duties & 159 & $54.3 \%$ \\
\hline Physical assessment & 158 & $53.9 \%$ \\
\hline Running outpatient clinics & 155 & $52.9 \%$ \\
\hline Coordinating home delivery of CFC & 152 & $51.9 \%$ \\
\hline Interpreting laboratory tests & 144 & $49.1 \%$ \\
\hline Clinical trials & 144 & $49.1 \%$ \\
\hline Haemophilia camps & 125 & $42.7 \%$ \\
\hline Nurse Research & 120 & $41.0 \%$ \\
\hline CFC stock management & 107 & $36.5 \%$ \\
\hline School visits & 106 & $36.2 \%$ \\
\hline $\begin{array}{l}\text { Ordering/requesting diagnostic imaging } \\
\text { tests }\end{array}$ & 105 & $35.8 \%$ \\
\hline Home visits & 98 & $33.4 \%$ \\
\hline Cleaning clinic/restocking supplies & 95 & $32.4 \%$ \\
\hline Outreach clinics & 87 & $29.7 \%$ \\
\hline Prescribing CFC & 85 & $29.0 \%$ \\
\hline Financial accountability/paperwork & 74 & $25.3 \%$ \\
\hline Drawing family trees & 71 & $24.2 \%$ \\
\hline Dictating & 66 & $22.5 \%$ \\
\hline Interpreting diagnostic imaging tests & 50 & $17.1 \%$ \\
\hline Telemedicine & 33 & $11.3 \%$ \\
\hline
\end{tabular}

Furthermore, nurses are recognized as being key players in promoting this evidence [1]. In the present survey, nurses across the world have identified similar areas of care that lack an evidence base and where nurse-led research could be undertaken to provide this evidence.

The high percentage of nurses educated to Baccalaureate degree level and beyond suggests that haemophilia nurses are well placed to impact day-to-day patient care. Nurses who are educated to degree level are known to have a positive impact on patient experience, outcomes and safety [3]. Advanced nursing practice, for example through supporting patients and families [4], promoting haemophilia care within hospital environments [5], delivering nurse-led clinics [6] is known to have a significant impact on patient care and outcomes [7]. Supporting development of haemophilia nurse advanced practice at an international level is possible through on-line nurse education, which is available in the United States of America [8]. A new Nursing Certification programme is now available in the United States as well which recognizes nurses who demonstrate expertise in hemostasis nursing through a portfolio submission [9]. Haemophilia nurse education and development in the UK has long been supported by an established competency framework [10] and there are currently moves underway to establish a standard curriculum for haemophilia nurses practicing within the European Union countries [11]. These frameworks include skills that are both generic and transferable (such as counselling and genetics) as well as haemophilia specific. To continue to develop the role of the nurse globally, the haemophilia nursing community needs to ensure that all nurses have access to accurate and current care and research data. Informed and educated nurses result in informed and educated patients. Together, this leads to improved patient experience and outcomes.

\section{Conclusion}

In the 2012 survey of UK nurses, it was reported that 'integrating research into clinical practice is problematic across nursing regardless of seniority, role, educational level or nursing culture' [2]. This study confirms that little has changed over the last four years, and that nurses struggle to incorporate research and evidence-based care into their day-to-day practice. What has changed significantly since 2012, is the recognition of haemophilia nurses as researchers who are able to support collaborative research locally, nationally and internationally. This is a key part of the haemophilia nurses remit and leads to improved care and better outcomes for patients and families affected by inherited bleeding disorders. This survey has demonstrated that nurses are willing and able to undertake nurse-led initiatives such as audit, service evaluation and research to enhance patient/family reported outcomes. The WFHNC is ideally placed to support this development through WFH outreach programmes, on-line education platforms and through on-going local support and education for nurses. Individually we can improve care for affected persons and their families, by sharing practice together we can improve care for many more. 


\section{Disclosures}

The authors have advised no interests that might be perceived as posing a conflict or bias.

This is an Open Access article distributed under the terms of the Creative Commons Attribution License (http:// creativecommons.org/licenses/by/2.0), which permits unrestricted use, distribution, and reproduction in any medium, provided the original work is properly cited.

\section{Acknowledgements}

The authors wish to thank all of the haemophilia nurses who participated in the survey.

\section{References}

1. Colvin BT, Astermark J, Fischer K, Gringeri A, Lassila R, Schramm W, Thomas A, Ingerslev J; Inter Disciplinary Working Group. European principles of haemophilia care. Haemophilia 2008;14:361-74. doi: 10.1111/j.1365-2516.2007.01625.x.

2. Khair K, Holland M, Vidler V, Loran C, Harrington C. Why don't haemophilia nurses do research? Haemophilia 2012:18;540-543. doi: 10.1111/j.1365-2516.2012.02749.x

3. McDonnell A, Goodwin E, Kennedy F, Hawley K, Gerrish K, Smith C. An evaluation of the implementation of Advanced Nurse Practitioner (ANP) roles in an acute hospital setting. J Adv Nurs 2011;67:2004-14

4. Gregorowski A, Brennan E, Chapman S, Gibson F, Khair K, May L, Lindsay-Waters A. An action research study to explore the nature of the nurse consultant role in the care of children and young people. J Clin Nurse 2013;1-2:201-10. doi: 10.1111/j.1365-2702.2012.04140.x.

5. Forrester C, Bielby H, Johns S, Efford J, Holland M, Khair K; United Kingdom Haemophilia Nurse's Association. Potential for development of haemophilia link nurse role within UK hospitals. Haemophilia 2013;19:57882. doi: $10.1111 /$ hae. 12144.

6. O'Shea E, Coughlan M, Corrigan H, McKee G. Evaluation of a nurse-led haemophilia counselling service. Br J Nurs 2012;14:868-70.

7. Aiken L, Clarke S, Cheung R, Sloane D, Silber J. Educational levels of hospital nurses and surgical patient mortality. J Am Medic Assoc 2003;290:1617-1623.

8. Partners in Bleeding Disorder Education available at www.partnersprn. org Last accessed 3 June 2016

9. American Nurses Credentialing Center (ANCC) http://nursecredentialing. org/HemostasisNursing (accessed June 14, 2016).

10. Khair K, Barker C, Bedford M, Elliott D, Harrington C, Lawrence K, Mackett N, Pollard D. A core competency framework for haemophilia nurses in the UK. J Haem Pract 2013; 1(1):J Haem Pract 2014; 1(1): 3236. doi: $10.17225 / \mathrm{jhp} .00010$ also available at www.haemnet.com Last accessed 3 June 2016.

11. Harrington C, Bedford M, Andritschke K, Barrie A, Elfvinge P, Grønhaug S, Mueller-Kagi E, Leenders B, Schrijvers LH. A European curriculum for nurses working in haemophilia. Haemophilia 2016;1:103-9. doi: 10.1111/ hae.12785.

\section{The Journal of} Haemophilia Practice

\section{An open-access} journal for sharing experience in the care of people with bleeding disorders

\section{www.haemjournal.com}

